\title{
Proteomics of autism and Alzheimer's mouse models reveal common alterations in mTOR signaling pathway
}

\author{
Shira Mencer ${ }^{1,2}$, Maryam Kartawy ${ }^{1,2}$, Felix Lendenfeld ${ }^{1}$, Huda Soluh ${ }^{1}$, Manish Kumar Tripathi ${ }^{1}$, Igor Khaliulin ${ }^{1}$ and Haitham Amal ${ }^{1}{ }^{凶}$
}

(c) The Author(s) 2021

Autism spectrum disorder (ASD) and Alzheimer's disease (AD) are two different neurological disorders that share common clinical features, such as language impairment, executive functions, and motor problems. A genetic convergence has been proposed as well. However, the molecular mechanisms of these pathologies are still not well understood. Protein S-nitrosylation (SNO), the nitric oxide (NO)-mediated posttranslational modification, targets key proteins implicated in synaptic and neuronal functions. Previously, we have shown that NO and SNO are involved in the InsG3680(+/+) ASD and P301S AD mouse models. Here, we performed largescale computational biology analysis of the SNO-proteome followed by biochemical validation to decipher the shared mechanisms between the pathologies. This analysis pointed to the mammalian target of rapamycin complex 1 (mTORC1) signaling pathway as one of the shared molecular mechanisms. Activation of mTOR in the cortex of both mouse models was confirmed by western blots that showed increased phosphorylation of RPS6, a major substrate of mTORC1. Other molecular alterations affected by SNO and shared between the two mouse models, such as synaptic-associated processes, PKA signaling, and cytoskeleton-related processes were also detected. This is the first study to decipher the SNO-related shared mechanisms between SHANK3 and MAPT mutations. Understanding the involvement of SNO in neurological disorders and its intersection between ASD and AD might help developing an effective novel therapy for both neuropathologies.

Translational Psychiatry (2021)11:480; https://doi.org/10.1038/s41398-021-01578-2

\section{INTRODUCTION}

Autism spectrum disorder (ASD) is a neurodevelopmental disorder associated with impaired social skills, restricted/repetitive behaviors, and communication deficits [1]. Patients may display co-occurring symptoms like seizures, anxiety, and attention deficits hyperactivity disorder [2]. ASD is prevalent in $\sim 1.5 \%$ of the population [3] and dramatic growth in the prevalence rates of this disorder has been reported over the last few decades [4]. The increase in the number of people with ASD has led to a very significant negative impact on the economy. In the US alone, the economic burden of this disorder was estimated at $\$ 268$ billion in 2015 [5]. Existing treatments offer little benefit for the core symptoms, making the search for novel treatment options necessary [6].

Alzheimer's disease (AD) is a neurodegenerative disease that comprises up to $80 \%$ of all dementias and affects $10 \%$ of the population aged 65 and older. Characteristic symptoms that severely impair the ability to perform everyday activities at the late stage of the disease include the progressive loss of memory, decline of cognitive skills, and deterioration of speech [7]. Despite global efforts to identify treatments against this pathology, only the treatments able to alleviate some symptoms of $A D$ are currently available. Recognizing the need for additional therapeutic strategies against $A D$, the World Health Organization has made this disease a public health priority [8].

The two hallmark features defining $A D$ are neurofibrillary tangles representing aggregates of twisted strands of hyperphosphorylated tau protein, and amyloid plaques mainly made up of accumulations of amyloid- $\beta(A \beta)$ peptides [7]. Proteolytic cleavage of the mature $A \beta$ protein precursor (APP) by $\beta$ - and $\gamma$-secretase via the amyloidogenic pathway generates neurotoxic $A \beta$ peptides consisting of 40 and 42 amino acids, which aggregate to make up the main components of neurotic plaques resulting in brain atrophy in individuals with $A D$ [9]. Alternative, non-amyloidogenic processing of APP by $a-$ and $y$-secretase, produce the secreted $a$-form of APP $(\mathrm{SAPPa})$, which is generally recognized as neurotrophic and neuroprotective [10]. These properties of sAPPa have made it a target for the treatment of neurodegenerative diseases such as $A D$ $[11,12]$. Interestingly, in addition to age-related neurodegenerative diseases, tau and the amyloid- $\beta$ protein precursor (APP) have also been shown to play a role in neurodevelopmental disorders such as autism $[6,13-15]$. Thus, it has been found that the level of sAPPa is elevated in severe (but not mild or moderate) autism [13-15]. It is suggested that promotion of the neurotrophic non-amyloidogenic pathway resulting in SAPPa accumulation in autistic patients leads to early megalencephaly, causing interneuronal misconnections potentially underlying a number of autism-related symptoms [16].

Hyperphosphorylation of tau that presumably causes neurodegeneration in $A D$ patients [17] may also play a role in ASD pathogenesis. Thus, Tai et al. have shown in two distinct mouse models of ASD that a $50 \%$ tau reduction is sufficient to prevent or significantly diminish autism-like behaviors, megalencephaly, and epilepsy co-occurring in ASD subjects [6]. The study also found

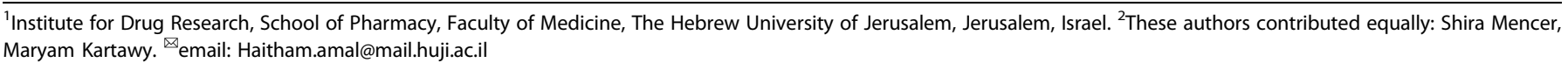

Received: 30 March 2021 Revised: 3 August 2021 Accepted: 20 August 2021

Published online: 17 September 2021 


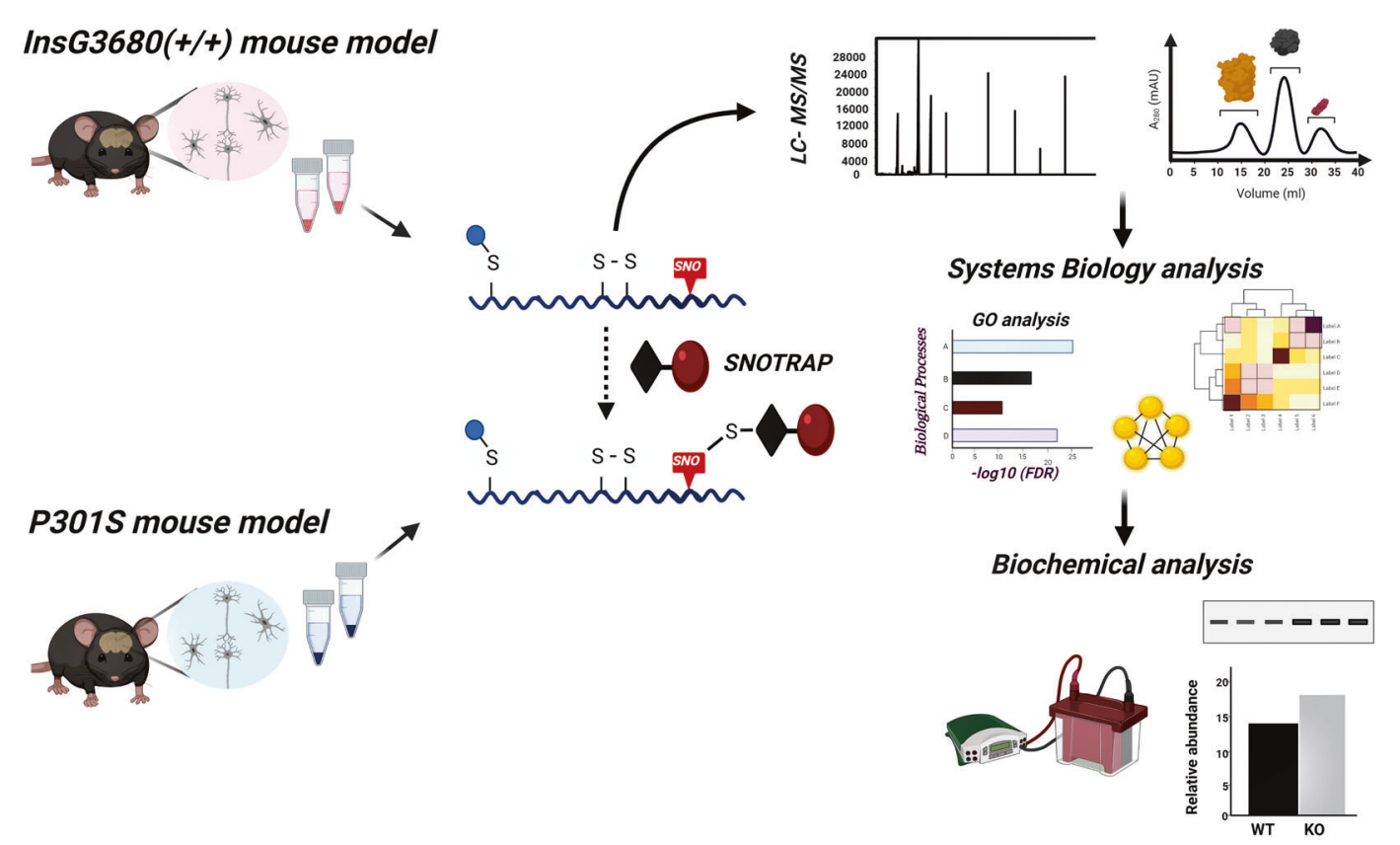

Fig. 1 Schematic workflow of the study. Schematic workflow of the SNOTRAP-based MS analysis of the ASD and AD cortex samples followed by large-scale systems analysis and biochemical validation.

that a reduction of tau increased the activity of PTEN, a suppressor of the PI3K/Akt/the mammalian target of rapamycin (mTOR) signaling pathway. The PI3K/Akt/mTOR pathway is commonly overactivated in ASD [18-20], and the authors postulated that various symptoms of ASD caused by aberrant activation of this signaling pathway could be counteracted by a reduction in tau levels [6].

Another link between AD and ASD has been established by Gozes and colleagues [21-23]. Activity-dependent neuroprotective protein (ADNP) regulates more than 400 genes during neurodevelopment and is essential for brain formation and neurogenesis [23]. De novo mutations of ADNP resulted in developmental delays and intellectual disabilities, including motor and speech dysfunctions [24, 25], and are estimated to occur in at least $0.17 \%$ of all ASD cases, making it one of the most common genes implicated in autism $[22,23]$. Meanwhile, ADNP deficiency has been reported to promote tauopathy in $A D$ patients $[23,26,27]$. Furthermore, a number of ADNP variants have been discovered in the brains of postmortem AD patients, leading to the hypothesis that ADNP mutations also affect the aging brain and neurodegeneration when mutated in a mosaic fashion [21].

Increasing attention is being drawn to the role of S-nitrosylation (SNO) in neuropathology. Protein SNO is a posttranslational modification by which nitric oxide (NO) is covalently attached to a cysteine thiol of a protein to form an S-nitrosothiol leading to major implications for the functions and downstream signal transduction of this protein [28]. Recently, we have mapped the SNO-proteome in two different mouse models, an ASD model based on InsG3680(+/+) mutation of the Shank3 gene [29] and an AD model based on P301S mutation causing increased tau phosphorylation [30]. The P301S mutation in the human tau protein encoded by the MAPT gene is linked to frontotemporal dementia (https://www.cell. com/fulltext/S0896-6273(07)00030-X). Our experiments on the Shank3 model of ASD indicated that the InsG3680(+/ + ) mutation alters SNO-proteome, resulting in an enrichment of certain pathways and processes linked to ASD pathology [29]. Meanwhile, our experiments on the P301S AD mouse model have also revealed major changes in the SNO-proteome in the cortex suggesting that the SNO of proteins contributes to tau pathology through regulation of calcium and non-canonical Wnt signaling [30]. We suggest that ASD and AD pathogenesis may involve common SNO-related mechanisms.

In this study, we conduct a comparative analysis of the two models (the Shank3 model of ASD [31] and the P301S model of AD https://www.sciencedirect.com/science/article/pii/ S089662730700030X) to investigate the shared biological processes (BP) and pathways that might be affected by aberrant SNO signaling in neurodevelopmental and neurodegenerative disorders. For this purpose, we used SNOTRAPbased mass spectrometry (MS) technology [29] followed by systems biology analysis combined with bioinformatics. The key shared proteins were validated biochemically, see schematics workflow of this study in Fig. 1.

\section{MATERIALS AND METHODS}

\section{Materials, reagents, and animals}

Vivapsin $10 \mathrm{kDa}$ molecular weight cut-off (MWCO) filters were procured from Sartorius AG (Germany). For MS, acetonitrile (ACN) and distilled water were purchased from Sigma-Aldrich (St. Louis, MO). HPLC grade solvents were used for high-performance liquid chromatography (HPLC) and liquid chromatography-MS (LC-MS). Biotin-PEG3-propionic acid was derived from Chem Pep Inc. (Florida, USA). Sequencing-grade modified trypsin was provided by Promega (Wisconsin, USA). SNOTRAP-biotin synthesis and nuclear magnetic resonance analysis were performed as described previously [32].

All methods were carried out in accordance with the Hebrew University guidelines and regulations. Animal data previously generated were taken from the Pride Software mentioned below. All animal experiments were conducted in accordance with the Institutional Animal Care and Use Committee and the Association for Assessment and Accreditation of Laboratory Animal Care International. Mice were purchased from the Jackson laboratory. The juvenile male InsG3680 $(+/+)$ mice harbor the ASD patient-linked single guanine nucleotide $(G)$ insertion at cDNA position 3680, which leads to a frameshift and downstream premature stop codon. The juvenile male tau P301S mice harbors the T34 isoform of microtubule-associated protein tau with one $\mathrm{N}$-terminal insert and four microtubule-binding repeats (1N4R) encoding the human P301S mutation.

\section{Brain tissue sample preparation for MS}

All samples were prepared in the dark at room temperature. Cortex tissues were isolated from juvenile (6-8 weeks) ASD, AD, and WT mice following 
decapitation during the daytime as described previously [33]. The brain samples were immediately transferred into liquid nitrogen and stored at $-80^{\circ} \mathrm{C}$ for further analysis. Per each of the biological replicate, three cortex tissue samples from three mice were pooled. Two biological replicates each containing three technical replicates were run. Further, tissues were homogenized on ice in freshly prepared lysis buffer containing: $250 \mathrm{mM}$ HEPES-NaOH, $0.1 \mathrm{mM}$ neocuproine, $1 \mathrm{mM}$ EDTA, 1\% NP-40, $20 \mathrm{mM}$ iodoacetamide (IAM), $1 \%$ protease inhibitors cocktail, $\mathrm{pH}$ 7.7. The homogenates were centrifuged $\left(12,000-13,000 \mathrm{~g}\right.$ for $10 \mathrm{~min}$ at $4{ }^{\circ} \mathrm{C}$ ), the supernatant was collected, and protein concentration was estimated by Bradford assay (Bio-Rad, California USA, Cat. No. 500-0006). Next, in the presence of $2.5 \%$ SDS, samples were alkylated with $30 \mathrm{mM}$ IAM in the dark at $37^{\circ} \mathrm{C}$. After alkylation, samples were washed twice with three times volume of $8 \mathrm{M}$ urea (in $50 \mathrm{mM}$ HEPES, $\mathrm{pH}$ 7.7) and once with $50 \mathrm{mM}$ HEPES (pH 7.7) by centrifugation at $5000 \mathrm{~g}$ for $30 \mathrm{~min}$ at $4{ }^{\circ} \mathrm{C}$ with $10 \mathrm{~K}$ MWCO spin filters pre-rinsed once with water (Sartorius AG, Germany, Cat. No. VS15T01). After the centrifugation, SNOTRAP-labeling stock solutions (in $50 \%$ ACN) were added to all samples to reach a final concentration of $1.25 \mathrm{mM}$. This was performed with the purpose of converting SNO to stable disulfide-iminophosphorane. Further, at $25^{\circ} \mathrm{C}$, all samples were incubated for $1.5 \mathrm{~h}$ in SNOTRAP solution. Succeeding the SNOTRAP labeling, the reagents were removed by three consecutive washing with $50 \mathrm{mM}$ HEPES ( $\mathrm{pH}$ 7.7) buffer with $10 \mathrm{~K}$ filters. Post ultrafiltration, each sample was incubated with $200 \mu \mathrm{l}$ pre-rinsed Streptavidin agarose beads (Pierce, Cat. No. 20349) for $1 \mathrm{~h}$ at room temperature with gentle shaking. The beads were washed with washing buffer (50 mM HEPES, $150 \mathrm{mM} \mathrm{NaCl}, 0.1 \%$ SDS, $\mathrm{pH}$ 7.7) three times and then with another washing buffer (50 mM HEPES, $\mathrm{pH}$ 7.7) three times. Following washing, proteins were eluted with the buffer containing: $10 \mathrm{mM}$ TCEP in $50 \mathrm{mM}$ HEPES, pH 7.7, and then alkylated with $10 \mathrm{mM}$ IAM. Protein samples were then trypsinized (Promega, Wisconsin, USA, Cat. No. V5111) at $37^{\circ} \mathrm{C}$ for $4 \mathrm{~h}$ and then desalted with C18 StageTips as described previously [34].

\section{Analysis flowchart of MS}

The digested peptides were analyzed using the 6550 Nano-HPLC-Chip/ MS system of Agilent coupled with a micro-autosampler, pumps of a capillary and nanoflow, the Chip-Cube connected to the LC modules, and the MS instrument. $\mathrm{H}_{2} \mathrm{O}$ with $0.1 \%$ formic acid (FA) was used as a mobile phase $A$ and $A C N$ with $0.1 \%$ FA was used as a mobile phase $B$. Polaris-HR-Chip-3C18 HPLC-Chip (Agilent Technologies, Cat. No. G424062030) separated the peptides. It consisted of a $360 \mathrm{nl}$ enrichment column, a $75 \mu \mathrm{m} \times 150 \mathrm{~mm}$ analytical column, and a $3 \mu \mathrm{m}$ stationary phase. The peptides were loaded into the enrichment column. The gradient was set for $55 \mathrm{~min}$, starting from $3 \% \mathrm{~B}$ at $300 \mathrm{nl} / \mathrm{min}$, increased to $30 \% \mathrm{~B}$, and kept from the 2 nd to 35 th $\mathrm{min}$, then increased to $60 \% \mathrm{~B}$ at the 40 th $\mathrm{min}$, to $90 \% \mathrm{~B}$ at the 45 th $\mathrm{min}$ and then kept stable for $5 \mathrm{~min}$ followed by a 5 min after-run at $3 \% \mathrm{~B}$. We acquired the positive-ion MS spectra using $1700 \mathrm{Da}$ extended dynamic range mode: electrospray ionization ESI capillary voltage was set on $1960 \mathrm{~V}$; fragmentor on $360 \mathrm{~V}$; Octopole RF peak on $750 \mathrm{~V}$; drying gas on $13 \mathrm{l} / \mathrm{min}$; drying temperature on $225^{\circ} \mathrm{C}$. The data were acquired at the rate of $6 \mathrm{MS}$ spectra/sec and 3 MS/MS spectra/s in the range of $\mathrm{m} / \mathrm{z} 300$ to 1700 for MS and 50 to 1700 for MS/MS. The max number of precursors per cycle was set at 20 , setting the threshold at 5000 ions in a precursor abundance-based scan speed in peptide isotope model with plus 2, plus 3, and above charge-state preference, and with active exclusion after one spectrum and released after $0.15 \mathrm{~min}$. The fragmentation energy was set at a slope of $3.1 \mathrm{~V} /$ $100 \mathrm{Da}$, including a 1.0 offset for doubly charged precursors, $3.6 \mathrm{~V} /$ $100 \mathrm{Da}$ with a -4.8 offset for triply and also multiply charged precursors. We used Agilent MassHunter Workstation software for the data acquisition. The mass accuracy was preserved using ion $\mathrm{m} / \mathrm{z} 1221.9906$ as an internal reference.

\section{Processing of the MS data}

For peak list generation, database searching, and false discovery rate (FDR) estimation, Agilent Spectrum Mill MS proteomics Workbench B.05 software was used. The following parameters for data extractions were conducted: precursor $\mathrm{MH}+300-8000 \mathrm{Da}$, scan time range from 0 to $200 \mathrm{~min}$, a sequence tag length of $>1$, default for precursor charge, true for find $12 \mathrm{C}$ precursor, merge scans with the same precursor at $\pm 30 \mathrm{~s}$ and $\pm 0.05 \mathrm{~m} / \mathrm{z}$, and a MS noise threshold of 100 counts. MS/MS spectra were searched against the mouse SwissProt protein database with $\pm 20 \mathrm{ppm}$ precursor ion tolerance and $\pm 50 \mathrm{ppm}$ fragment ion tolerance. Different modifications of methionine oxidation, deamidation of asparagine, and a fixed modification of cysteine carbamidomethylation were included. The generated FDR was set at $1.2 \%$ for both peptide and protein identification. The MS proteomics data used in this study, which we generated previously, were taken from ProteomeXchange Consortium database (http://proteomecentral.proteomexchange.org) via the PRIDE partner repository with the dataset identifier <PXD006907 $>$ for ASD data and <PXD010106 > for AD data.

\section{Statistics and systems biology analysis}

For the systems biology analysis of the BP and pathways analysis, we uploaded the lists of all SNO proteins into MetaCore from Clarivate Analytics (MetaCore V6.34 build 69200 software). The Benjamini-Hochberg correction [35] was used to calculate the $P$ value and generate FDR. Terms with FDR values below 0.05 were accepted. The search tool for the interacting proteins (STRING, version 10.0) was used to analyze the protein-protein interaction of SNO proteins (http://string-db.org) [36] Strong reliability interactions (score $>0.7$ ) from the neighborhood, gene fusion, co-occurrence, co-expression, experiments, databases, and text mining lists were used. Cytoscape V3.3.0 software was used for visualization of the protein-protein interaction. MetaCore from Clarivate Analytics (MetaCore V6.34 build 69200 software) was used for the network generation after submitting the lists of SNO proteins. For this purpose, we also used Benjamini-Hochberg correction to calculate the $P$ value and generate FDR. The processes/terms with the FDR values below 0.05 were included. GraphPad PRISM 8 software was used to generate the schematic figure and heat map.

\section{Western blot}

Protein extraction and estimation. The cortex tissue was homogenized and sonicated in RIPA buffer (Sigma-Aldrich, USA, Cat. No. R0278) containing protease and phosphatase inhibitors cocktail, centrifuged at $4{ }^{\circ} \mathrm{C}$, and the supernatant was collected. Protein content was measured in the supernatant using the BCA (Sigma-Aldrich, USA, Cat. No. B9643) method.

$W B$ analysis. The protein content in the samples was estimated and then subjected to polyacrylamide gel electrophoresis (Bio-Rad \#1610185), followed by wet transfer onto a polyvinylidene fluoride (PVDF) membrane (Bio-Rad \#1620177). Non-specific-binding sites were blocked by 5\% BSA in tris-buffered saline $(135 \mathrm{mM} \mathrm{NaCl}, 2.5 \mathrm{mM} \mathrm{KCl}, 50 \mathrm{mM}$ Tris, and $0.1 \%$ Tween $20, \mathrm{pH}$ 7.4) for $2 \mathrm{~h}$ at room temperature (RT). PVDF membrane with the transferred proteins were incubated with the primary antibody of anti-pRPS6 (dilution 1:1000; Cell Signaling Technology, \#4858), anti-RPS6 (dilution 1:1000; Cell Signaling Technology \#2317), anti-beta-actin (dilution 1:1000; Cell Signaling Technology \#3700) overnight at $4{ }^{\circ} \mathrm{C}$ on a shaker. After the incubation with the primary antibodies, the membrane was washed with TBST buffer and incubated with anti-mouse/rabbit horseradish peroxidase-conjugated secondary antibody for $1 \mathrm{~h}$ at RT. Specific binding of the protein of interest was detected using ECL substrate (BioRad \#1705062). The bands were visualized using a Bio-Rad Chemidoc imaging system.

\section{RESULTS BP analysis of the SNO-proteome in ASD and AD mouse models}

Proteomic analysis using the SNOTRAP-based MS tool revealed 550 proteins that are exclusive to ASD mouse model, 304 proteins exclusive to $A D$, and 51 proteins shared between the two groups. See the Venn diagram in Fig. 2A. Table 1 shows the list of SNO proteins shared between the two models. The detailed lists of the SNO proteins in both groups are presented in Supplementary Table 1.

The BP analysis was performed to identify the biological mechanisms that are modulated by SNO in both models. This analysis demonstrated significant enrichment of synaptic and neuronal processes that appeared to be common to both Shank3 and P301S models. Thus, modulation of chemical synaptic transmission (false discovery rate $(F D R)=1.10 E-14$ in $A S D$, $\mathrm{FDR}=1.13 \mathrm{E}-02$ in $\mathrm{AD}$ ), regulation of trans-synaptic signaling (FDR $1.20 \mathrm{E}-14$ in $\mathrm{ASD}, \mathrm{FDR}=1.16 \mathrm{E}-02$ in $\mathrm{AD}$ ), nervous system 
Table 1. The shared SNO-proteins between ASD and AD models.

\begin{tabular}{|c|c|}
\hline Accession ID & Protein's name \\
\hline P06837 & Neuromodulin \\
\hline P34884 & Macrophage migration inhibitory factor \\
\hline Q7SIG6 & $\begin{array}{l}\text { Arf-GAP with SH3 domain, ANK repeat and PH domain-containing } \\
\text { protein } 2\end{array}$ \\
\hline Q6R5N8 & Toll-like receptor 13 \\
\hline Q6PIX9 & Uncharacterized protein C17orf80 homolog \\
\hline A2AF47 & Dedicator of cytokinesis protein 11 \\
\hline Q8BLQ9 & Cell adhesion molecule 2 \\
\hline Q6ZQA0 & Neurobeachin-like protein 2 \\
\hline Q8BXQ2 & GPI transamidase component PIG-T \\
\hline Q5QNQ9 & Collagen alpha-1 (XXVII) chain \\
\hline Q3UR32 & P2X purinoceptor 3 \\
\hline Q9JJ26 & Pyrin \\
\hline Q6XQHO & Galactose-3-O-sulfotransferase 2 \\
\hline Q6RHR9 & $\begin{array}{l}\text { Membrane-associated guanylate kinase, WW and PDZ domain- } \\
\text { containing protein } 1\end{array}$ \\
\hline P41234 & ATP-binding cassette sub-family A member 2 \\
\hline Q8CFA1 & Interleukin-1 receptor-associated kinase-like 2 \\
\hline Q8C9B9 & Death-inducer obliterator 1 \\
\hline A2AAE1 & Uncharacterized protein KIAA1109 \\
\hline Q8BMS1 & Trifunctional enzyme subunit alpha, mitochondrial \\
\hline Q9Z329 & Inositol 1,4,5-trisphosphate receptor type 2 \\
\hline Q8BI84 & Melanoma inhibitory activity protein 3 \\
\hline Q9D5V5 & Cullin-5 \\
\hline Q6PFX7 & $\begin{array}{l}\text { Neuronal tyrosine-phosphorylated phosphoinositide-3-kinase } \\
\text { adapter } 1\end{array}$ \\
\hline Q8BUV3 & Gephyrin \\
\hline E9Q557 & Desmoplakin \\
\hline Q02257 & Junction plakoglobin \\
\hline Q9CQ48 & NudC domain-containing protein 2 \\
\hline Q9WUS4 & Gap junction alpha-10 protein \\
\hline Q9D4K4 & FANCD2 opposite strand protein \\
\hline O35166 & Golgi SNAP receptor complex member 2 \\
\hline O55047 & Serine/threonine-protein kinase tousled-like 2 \\
\hline Q7TT50 & Serine/threonine-protein kinase MRCK beta \\
\hline Q80X90 & Filamin-B \\
\hline A2AU72 & Armadillo repeat-containing protein 3 \\
\hline Q06890 & Clusterin \\
\hline 088455 & 7-Dehydrocholesterol reductase \\
\hline Q587J6 & LINE-1 type transposase domain-containing protein 1 \\
\hline Q3V1U8 & ELMO domain-containing protein 1 \\
\hline Q6PDI5 & Proteasome-associated protein ECM29 homolog \\
\hline Q06335 & Amyloid-like protein 2 \\
\hline Q8BGQ7 & Alanine-tRNA ligase, cytoplasmic \\
\hline Q8C779 & Uncharacterized protein CXorf57 homolog \\
\hline Q9QZE7 & Translin-associated protein $X$ \\
\hline Q9QZQ1 & Afadin \\
\hline Q91Y44 & Bromodomain testis-specific protein \\
\hline Q8BUH8 & Sentrin-specific protease 7 \\
\hline Q3UQ44 & Ras GTPase-activating-like protein IQGAP2 \\
\hline Q8CHY6 & Transcriptional repressor p66 alpha \\
\hline Q6PGA0 & REST corepressor 3 \\
\hline Q00558 & Factor VIII intron 22 protein \\
\hline Q91ZU6 & Dystonin \\
\hline
\end{tabular}

development ( $F D R=3.21 \mathrm{E}-17$ in $\mathrm{ASD}, \mathrm{FDR}=4.86 \mathrm{E}-11$ in $\mathrm{AD}$ ), and others have found to be enriched (Fig. 2B).

\section{Pathways analysis of the SNO-proteome in ASD and AD mouse models}

Pathways analysis of the SNO proteins that are exclusive to ASD and exclusive to $A D$ revealed common enrichment of pathways affected in both models including WNT/beta-catenin signaling in the cytoplasm ( $F D R=6.72 \mathrm{E}-03), \mathrm{HTR} 2 \mathrm{~A}$ signaling in the nervous system (FDR $=3.00 \mathrm{E}-04)$, the role of PKA in cytoskeleton organization (FDR $=1.37 \mathrm{E}-03$ ), and others (Fig. 2C).

Importantly, our analysis revealed the involvement of the SNO proteins in the mammalian target of rapamycin complex 1 (mTORC1) upstream signaling pathway (FDR $=5.98 \mathrm{E}-03$ ). A subset of proteins that are associated with both ASD and AD showed to be involved in the mTOR signaling pathway. These include RAC1, WNT11, Frizzled10 in AD and TSC2, P38 MAPK, AGTR1, PDGF receptor, $\mathrm{mLST} 8$, and insulin receptor in ASD mice (Fig. 2C). Supplementary Table 2 summarizes the systems biology analysis of both models.

\section{Interactome and clustering analysis of the SNO proteins}

The proteins were classified into clusters based on their enriched biological processes and pathways. Different subsets of SNO proteins exclusive to $A S D$ and $A D$ formed distinct clusters belonging to the same biological processes and pathways that are suggested to contribute to the pathogenesis of ASD and AD. The yellow-ASD and green-AD nodes in Fig. 3 correspond to the SNO proteins that are involved in "Modulation of chemical synaptic transmission", including SYN1, STX1A, JAK2, and others in ASD (Fig. 3A) and TBCD, RAC1, P2RX3, SYT14, and others in AD (Fig. 3B). Furthermore, the involvement of PKA in cytoskeleton reorganization was found to be common to both models as well. The gray-ASD nodes included CYP51, CFI1, ADD2, and others (Fig. $3 C$ ) and the blue-AD nodes included BANK1, GNAS, GABBR1, and others (Fig. 3D).

\section{Biochemical analysis of mTORC1 pathway}

To validate our bioinformatics analysis and test whether the mTORC1 signaling pathway is altered in both models, we quantified the phosphorylation levels of a major substrate of the mTORC1, ribosomal protein S6 (RPS6). In ASD, WB analysis showed significantly elevated levels of the phospho-RPS6 (P-RPS6) in the mutant ASD mice compared to their wild-type (WT) counterparts (Fig. 4A, B). A significant increase of P-RPS6 was also observed in the mutant AD mice compared to the WT (Fig. 4C, D). Increased phosphorylation of the RPS6 indicates hyperactivation of mTORC1 in both pathologies (Fig. 5).

\section{DISCUSSION}

Molecular alterations, including different proteins and signaling pathways, associated with aberrant S-nitrosylation were found in both Shank3 (ASD model) and P301S (AD model) mutant mice in this study. The SNO-related enrichment of synaptic-associated processes, serotonin 2A receptor (HTR2A) signaling, regulation of the cytoskeleton-related processes, and MTOR signaling were found to be shared between the two mouse models. These findings may provide mechanistic insight into the changes occurring to the S-nitroso-proteome that potentially can lead to the neuropathology.

$\mathrm{NO}$ is a multifunctional signaling molecule, that takes part in the regulation of neuronal and synaptic functions [29, 33, 37]. NO affects cellular signaling through cyclic GMP formation, proteins S-nitrosylation (SNO), tyrosine nitration, and S-nitrosoglutathione (GSNO) formation. SNO is a reversible NO-mediated posttranslational modification of cysteine thiols of proteins that modulate cell signaling pathways, neuronal functions, and synaptic plasticity $[29,30,33,37-41]$. SNO occurs in different neuroanatomical regions, including the cortex, hippocampus, and striatum [42]. It contributes to multiple physiological and neuropathological processes. Thus, recently, we have shown a reprogramming of the S-nitroso-proteome during the aging process [37] and in response to arsenic exposure [43]. Further, we found significant sex differences in the NO and SNO-related biological functions in 
A)

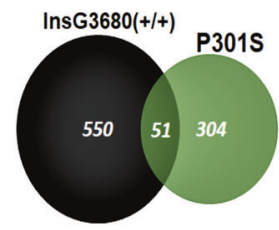

B)

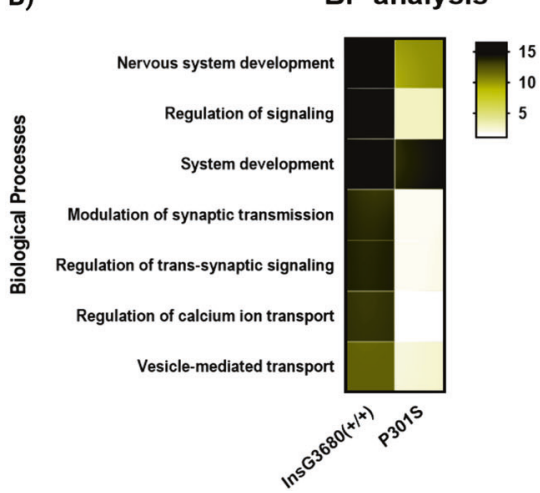

C)

Pathways analysis

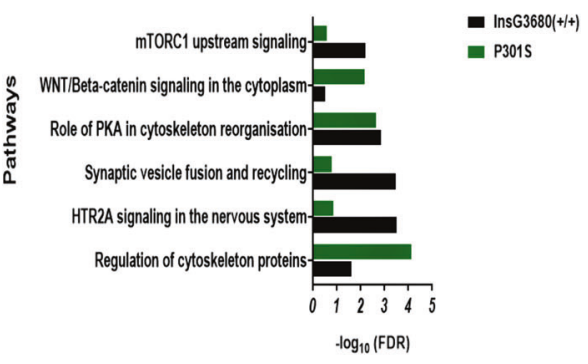

Fig. 2 Systems biology analysis of the SNO proteins of the ASD and AD cortex samples. A Venn diagram of the SNO proteins. B Heat map representing the BP analysis conducted on the SNO proteins exclusive to ASD and AD models. *The scale represents the -log10 of the corrected false discovery rate (FDR). C Pathways analysis of the SNO proteins exclusive to ASD and AD models. *Bars represents the -log10 of the Benjamini corrected false discovery rate (FDR).

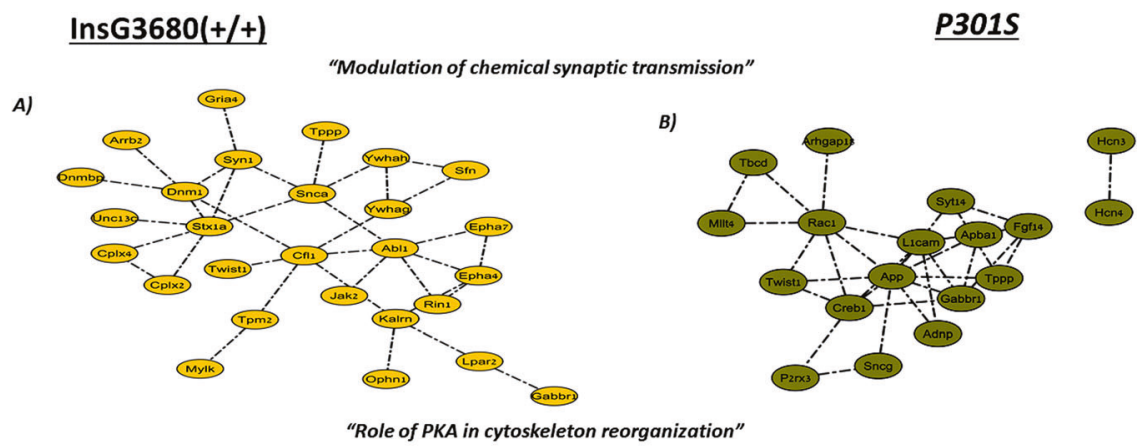

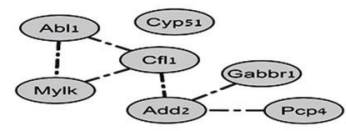

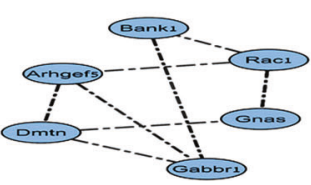

Fig. 3 Clustering analysis of the SNOed proteins in ASD and AD mouse models. "Modulation of chemical synaptic transmission" cluster was enriched in A ASD and B AD, and the "role of PKA in cytoskeleton reorganization" cluster was enriched in C ASD and D AD.

the cortex [33]. SNO of various proteins has been implicated in brain disorders, such as ASD [29, 41, 44], AD [30, 39, 41, 45, 46], Parkinson's disease $[41,47,48]$, Huntington's disease $[41,45,46,48,49]$, schizophrenia [41, 50], and other diseases. In the case of ASD, we suggest that aberrant SNO signaling of key proteins leads to synaptic deficits that converge into behavioral deficits in the Shank3 mutant mice [29]. In the case of AD, it is still not clear how SNO affects the phenotype in the juvenile mice because at the age of 6-8 weeks there are no neuropathological features of AD. However, identification and characterization of the proteins that are S-nitrosylated in these mice might be an indicative for early diagnostic/pathological biomarkers of AD.

In our study, gene ontology (GO) analysis of the SNO proteins in ASD and AD mutant mice revealed enrichment of synapticassociated processes. In particular, modulation of synaptic transmission, regulation of trans-synaptic signaling, synaptic vesicle fusion, and recycling appeared to be enriched in the mutant mice (Fig. 2C). Several studies have reported that precise control of synaptic functions and connectivity is crucial for maintaining normal brain functioning and the breakdown of these functions might be attributed to both ASD and AD pathologies [51-56]. Considering the involvement of protein SNO in the enrichment of synaptic processes in both mouse models in our experiments, it is logical to suggest that aberrant SNO signaling may lead to synaptic dysfunction that might contribute to the pathogenesis of ASD and AD. However, future validation studies should be conducted to confirm it.

Enrichment of "HTR2A signaling in the nervous system" (Fig. 2C) was also found in both models. HTR2A is highly abundant in the mammalian cortex, controlling multiple cognitive functions. The serotonergic system has been implicated in several neuropathological and neuropsychological conditions including mood disorders, schizophrenia, ASD, AD, and other brain pathologies [57-60]. We suggest that altered SNO signaling under 
InsG3680(+/+)

A)

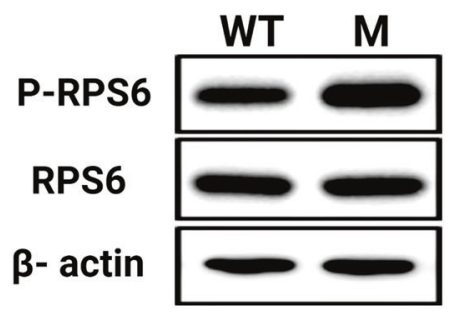

P301S

C)

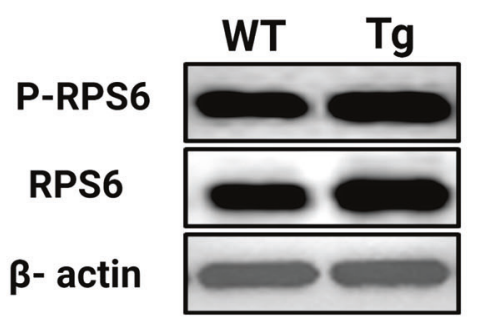

B)

P-RPS6/RPS6

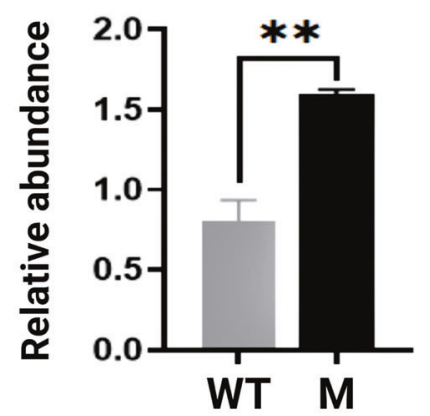

D)

P-RPS6/RPS6

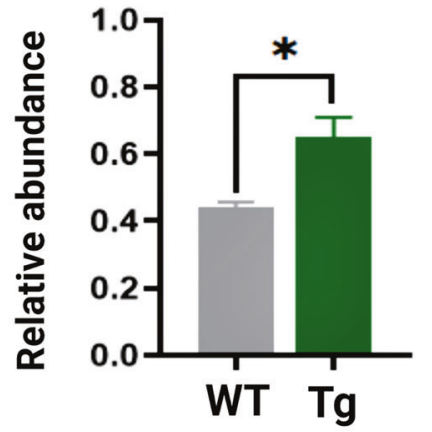

Fig. 4 WB analysis. A Representative WB of RPS6 and P-RPS6 prepared from the cortex tissues from the WT mice $(n=5)$ and ASD mouse model (abbreviated with $M ; n=5$ ). B The relative average WB intensity of P-RPS6, showing a significant increase in the phosphorylation levels of the RPS6 in mutant mice compared to the WT. The data are normalized to RPS6 and beta-actin presented as mean \pm SEM. A two-tailed $t$-test was conducted. ${ }^{* *} P<0.01$. C Representative WB of RPS6 and P-RPS6 prepared from the cortex tissues from the WT mice $(n=5)$ and AD mouse model (abbreviated with Tg; $n=5$ ). D The relative average WB intensity of P-RPS6, showing a significant increase in the phosphorylation levels of the RPS6 in Tg mice compared to their WT littermates. The data are normalized to RPS6 and beta-actin presented as mean \pm SD. A twotailed $t$-test was conducted. ${ }^{*} P<0.05$.

neuropathological conditions might affect the neuromodulatory system, including the serotonin system, and subsequently facilitate the pathogenesis of ASD and AD.

It is worth mentioning that our analysis indicated enrichment of "regulation of cytoskeleton proteins" (Fig. 2C). The cytoskeleton is essential for proper neuronal functioning, axon guidance, and synapse formation [61]. Growing evidence suggests that abnormalities of cytoskeleton-associated proteins might result in detrimental effects contributing to neurodevelopmental disorders such as ASD, intellectual disabilities, and neurodegeneration [61-64]. It can be suggested that SNO-related abnormalities in the cytoskeletal proteins represent another pathogenic mechanism shared between ASD and AD.

Importantly, our systems biology analysis revealed the enrichment of the "mTORC1 upstream signaling pathway" by a subset of SNO proteins that were exclusively found in ASD and AD mouse models (Fig. 5). This indicates the possibility of altering the mTOR signaling as a result of aberrant SNO of specific proteins during neurodevelopment and neurodegeneration. mTOR is a highly conserved serine/threonine kinase, which plays an essential role in multiple physiological functions in the central nervous system, including neuronal differentiation, proliferation (neurogenesis), survival, dendritic arborization, synaptic formation, axonal regeneration, and dendritic spines growth via the regulation of protein synthesis that occurs through the phosphorylation of at least two major downstream targets; the p70 ribosomal protein S6 kinase and eukaryotic translational initiation factor $4 \mathrm{E}$-binding protein 1 (el4E-BP1) [65-67]. Thus, given the importance of the mTOR, it is not surprising that pathological hyper- or hypo-activation of this signaling pathway is potentially associated with a spectrum of neuropathologies, such as abnormal neuronal development, intellectual and learning disabilities, seizures, mental retardation, and neuronal degeneration [67-70].

Our work showed that the tuberous sclerosis complex 2 (TSC2) was S-nitrosylated in the Shank3 model of ASD but not in WT mice (Figs. 2C and 5). TSC2 is an upstream master negative regulator of the mTOR activity. It forms a heterodimeric complex with TSC1 that suppresses mTORC 1 activity through inhibition of the small GTPase Rheb, an essential activator of mTORC1 [71, 72]. The inhibitory effect of TSC2 on mTOR signaling is known to play a critical role in axon guidance, myelination, synaptic plasticity, and other neuronal processes [71]. Meanwhile, it is accepted that overactivation of the mTOR signaling contributes to the pathology of ASD [66, 73, 74]. Following a previous study [75], we suggest that SNO of TSC2 would result its autoubiquitination and in impaired TSC2/TSC1 dimerization, leading to a constitutive overactivation of mTORC1 that would enhance the severity of ASD phenotypes. This hypothesis is consistent with the findings of Reith et al. who showed that loss of Tsc2 in Purkinje cells may result in autistic-like behavior in mice. To further confirm the impact of SNO on mTOR signaling in the ASD mouse models, we quantified the phosphorylation levels of a major substrate of 


\section{SNO proteins in P301S mouse model}

\section{SNO proteins in InsG3680(+/+) mouse model}

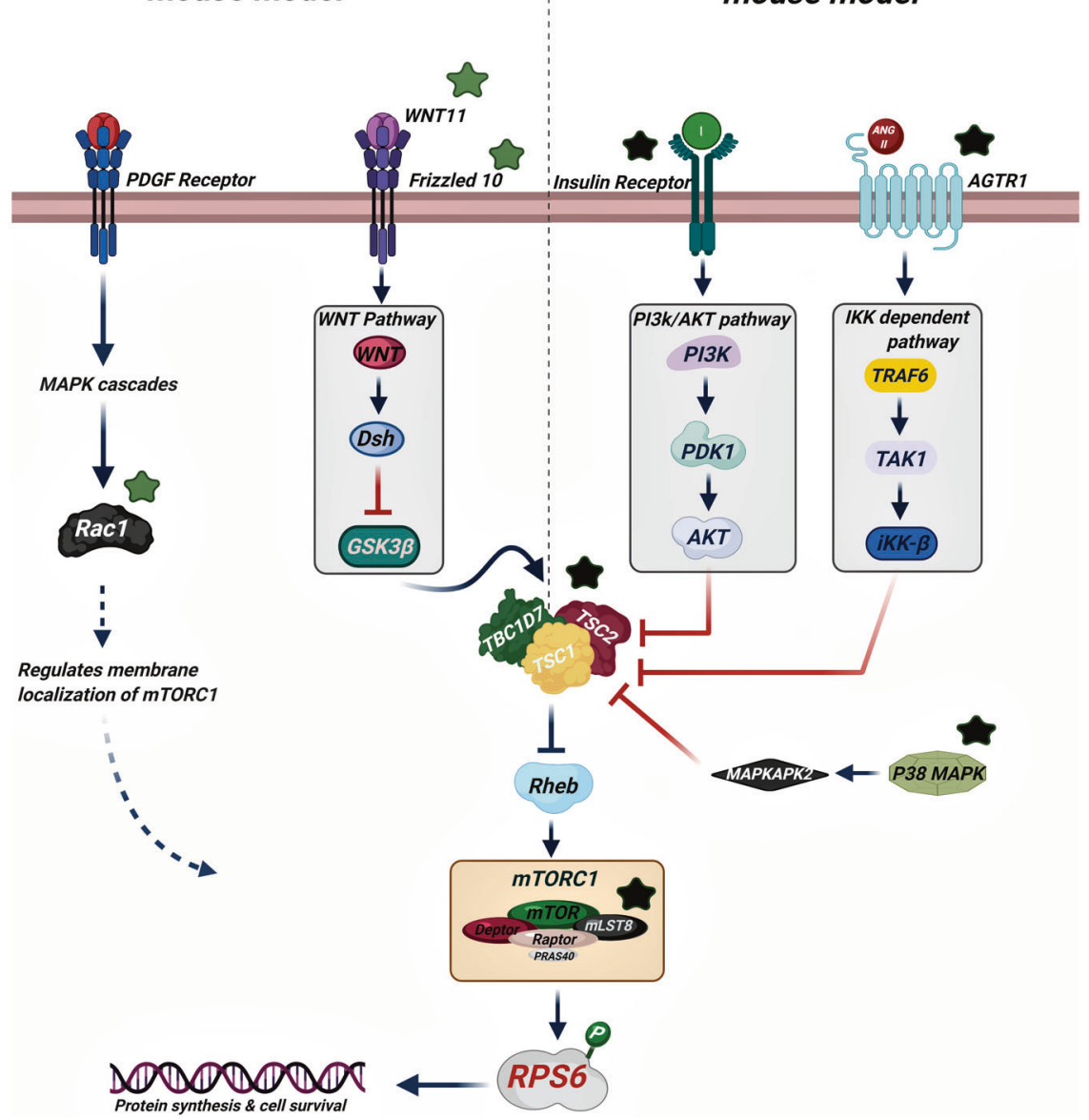

Fig. 5 The suggested scheme of the SNO-dependent mTOR activation in the ASD and AD mouse models. Green stars are SNO proteins in AD. Black stars are SNO proteins in ASD.

mTORC1, RPS6, that is widely used as a marker for neuronal activity and a readout of the mTORC1 activity [76]. The analysis showed increased RPS6 phosphorylation in the Shank3 mutant mice compared to the WT indicating increased activity of mTORC1, likely in response to the altered SNO signaling.

Our systems biology analysis revealed elevated SNO of WNT11 and Frizzled 10 in the P301S mutant mice (Figs. 2C and 5). These data are consistent with our previous studies showing that disruption of the WNT signaling is implicated in AD pathogenesis $[30,77]$. Interestingly, it has been found that the WNT signaling pathway can mediate mTORC1 activity through the inhibition of GSK3 $\beta$, a crucial regulatory kinase known to suppress mTORC1 by phosphorylating and activating TSC2 [78-80]. Increasing evidence $[81,82]$ points to the pivotal role of $\mathrm{mTOR}$ in multiple processes linked to $A D$, such as synaptic plasticity, aging, autophagy, longterm memory formation, etc. [83-85]. Some reports have indicated that reduced or increased mTOR signaling is associated with neurodegeneration $[81,82,86]$. These data prompted us to suggest that S-nitrosylation of the components of the WNT signaling pathway, such as WNT11 and Frizzled10, mediates dysregulation of this pathway resulting in altered mTOR signaling, which in turn contributes to AD pathology. Similar to the Shank3 mutant mice, WB analysis revealed elevated levels of RPS6 in the P301S mutant mice compared to their WT counterparts, suggesting hyperactivation of mTORC1 in the AD mouse model.

Taken together, our results indicate that SNO-mediated abnormal activation of the mTOR signaling is involved in the pathogenesis of both ASD and AD. However, further validation studies are needed to investigate the direct effect of SNO on this pathway in these pathologies.

A total of 51 proteins showed to be S-nitrosylated in both mouse models. These included proteins such as Gap43, Camd2, P2rx3, Itpr2, and Nyap1. Gap43 is a neuron-specific calmodulinbinding protein that is thought to play a key role in axonal growth, neurogenesis, neuroplasticity, and synaptic transmission [87-90]. Altered expression of Gap43 was observed in both ASD and AD [90-92]. Camd2 is a synaptic cell adhesion molecule engaged in synapse organization, formation, and neuronal development [93-96]. Abnormal expression of this protein has also been proposed to contribute to the pathology of ASD and AD $[95,97,98] . P 2 r x 3$ is an ionotropic ATP receptor that is mainly expressed in sensory afferent neurons and can functionally affect sensory transduction [99]. The accumulating evidence suggests a correlation between the changes in P2rx3 expression and the development of ASD and AD [100, 101]. Itpr2 has a centralized role in the processes of pruning improper synapses necessary for maintaining intact brain functioning [102]. Previous data suggest that deficiency in the Intpr2 is associated with both ASD and AD [102-104]. Nyap1 belongs to a family of phosphoproteins termed neuronal tyrosine-phosphorylated adaptor for the PI3-kinase (NYAP). Nyap1 is mainly expressed in the developing neurons and showed to play a pivotal regulatory role in neuronal morphogenesis, brain size, and neurite outgrowth via simultaneous activation of PI3K and the recruitment of the downstream effector, WAVE complex, to the PI3K [105]. It has been documented that disruption in Nyap1 also contributes to the 
pathogenesis of ASD and AD [105-107]. In line with these data, we suggest that aberrant SNO signaling induces functional changes to these proteins, affecting different processes and pathways related to neurodevelopment and neurodegeneration.

Our study showed that the SNOTRAP-based MS approach combined with large-scale systems biology analysis facilitates the global profiling of the SNO-proteome in both pathologies. Future studies of the effects of S-nitrosylation on these proteins may help to unravel the neuropathological mechanisms of ASD and AD. Finally, it is important to highlight that there are no data to indicate that such SNO-related abnormality is for all ASD and AD cases. Therefore, we emphasize that the shared mechanisms are specific to the two mutations investigated in this study.

In conclusion, our findings showed that the SNO signaling is altered by both mutations in Shank3 and Mapt genes. In both datasets, SNO targets a wide range of proteins implicated in the regulation of neurodevelopment and neurodegeneration. Remarkably, S-nitrosylation of many of these proteins could be involved in the pathogenesis of both ASD and AD. Several signaling pathways and biological processes affected by SNO were found to be common to both pathologies. These included synaptic-associated processes, HTR2A signaling, PKA and calcium-mediated signaling, regulation of the cytoskeleton-related processes, and mTOR signaling. These proteins and pathways might serve in the near future as drug targets for the treatment of ASD and AD.

\section{REFERENCES}

1. Sokol DK, Maloney B, Westmark CJ, Lahiri DK. Novel contribution of secreted smyloid- $\beta$ precursor protein to white matter brain enlargement in autism spectrum disorder. Front Psychiatry. 2019;10:165-165. https://doi.org/10.3389/ fpsyt.2019.00165.

2. Besag FM. Epilepsy in patients with autism: links, risks and treatment challenges. Neuropsychiatr Dis Treat. 2017;14:1-10. https://doi.org/10.2147/NDT. S120509.

3. Mullins C, Fishell G, Tsien RW. Unifying views of autism spectrum disorders: a consideration of autoregulatory feedback loops. Neuron. 2016;89:1131-56.

4. Thurm A, Swedo SE. The importance of autism research. Dialogues Clin Neurosci. 2012;14:219-22.

5. Leigh JP, Du J. Brief Report: Forecasting the economic burden of autism in 2015 and 2025 in the United States. J Autism Dev Disord. 2015;45:4135-9. https://doi. org/10.1007/s10803-015-2521-7.

6. Tai C, Chang CW, Yu GQ, Lopez I, Yu X, Wang X. et al. Tau reduction prevents key features of autism in mouse models. Neuron. 2020;106:421.e411. https://doi.org/ 10.1016/j.neuron.2020.01.038.

7. Association, A. S. 2020 Alzheimer's disease facts and figures. Alzheimers Dement. 2020;16:391-460. https://doi.org/10.1002/alz.12068.

8. Lane CA, Hardy J, Schott JM. Alzheimer's disease. Eur J Neurol. 2018;25:59-70. https://doi.org/10.1111/ene.13439.

9. Thinakaran G, Koo EH. Amyloid precursor protein trafficking, processing, and function. J Biol Chem. 2008;283:29615-9. https://doi.org/10.1074/jbc.R800019200.

10. Turner PR, O'Connor K, Tate WP, Abraham WC. Roles of amyloid precursor protein and its fragments in regulating neural activity, plasticity and memory. Prog Neurobiol. 2003;70:1-32. https://doi.org/10.1016/s0301-0082(03)00089-3.

11. Bandyopadhyay S, Goldstein LE, Lahiri DK, Rogers JT. Role of the APP nonamyloidogenic signaling pathway and targeting alpha-secretase as an alternative drug target for treatment of Alzheimer's disease. Curr Med Chem. 2007;14:2848-64. https://doi.org/10.2174/092986707782360060.

12. Habib A, Sawmiller D, Tan J. Restoring soluble amyloid precursor protein a functions as a potential treatment for Alzheimer's disease. J Neurosci Res. 2017;95:973-91. https://doi.org/10.1002/jnr.23823.

13. Bailey AR, Giunta BN, Obregon D, Nikolic WV, Tian J, Sanberg CD, et al. Peripheral biomarkers in autism: secreted amyloid precursor protein-alpha as a probable key player in early diagnosis. Int J Clin Exp Med. 2008;1:338-44.

14. Ray B, Long JM, Sokol DK, Lahiri DK. Increased secreted amyloid precursor protein-a (sAPPa) in severe autism: proposal of a specific, anabolic pathway and putative biomarker. PLoS ONE. 2011;6:e20405-e20405. https://doi.org/10.1371/ journal.pone.0020405.

15. Sokol DK, Chen D, Farlow MR, Dunn DW, Maloney B, Zimmer JA, et al. High levels of Alzheimer beta-amyloid precursor protein (APP) in children with severely autistic behavior and aggression. J Child Neurol. 2006;21:444-9. https://doi.org/ $10.1177 / 08830738060210062201$.
16. Lahiri DK, Sokol DK, Erickson C, Ray B, Ho CY, Maloney B. Autism as early neurodevelopmental disorder: evidence for an sAPPa-mediated anabolic pathway. Front Cell Neurosci. 2013;7:94. https://doi.org/10.3389/fncel.2013.00094.

17. Iqbal K, Liu F, Gong CX, Grundke-lqbal I. Tau in Alzheimer disease and related tauopathies. Curr Alzheimer Res. 2010;7:656-64. https://doi.org/10.2174/ 156720510793611592.

18. Ebert DH, Greenberg ME. Activity-dependent neuronal signalling and autism spectrum disorder. Nature. 2013;493:327-37. https://doi.org/10.1038/nature11860.

19. Enriquez-Barreto L, Morales M. The PI3K signaling pathway as a pharmacological target in autism related disorders and schizophrenia. Mol Cell Ther. 2016;4. https://doi.org/10.1186/s40591-016-0047-9.

20. Yeung KS, Tso W, Ip J, Mak C, Leung G, Tsang M, et al. Identification of mutations in the PI3K-AKT-mTOR signalling pathway in patients with macrocephaly and developmental delay and/or autism. Mol Autism. 2017;8:66 https://doi.org/ 10.1186/s13229-017-0182-4.

21. Ivashko-Pachima Y, Hadar A, Grigg I, Korenková V, Kapitansky O, Karmon G, et al. Discovery of autism/intellectual disability somatic mutations in Alzheimer's brains: mutated ADNP cytoskeletal impairments and repair as a case study. Mol Psychiatry 2019. https://doi.org/10.1038/s41380-019-0563-5.

22. Malishkevich A, Amram N, Hacohen-Kleiman G, Magen I, Giladi E, Gozes I. Activity-dependent neuroprotective protein (ADNP) exhibits striking sexual dichotomy impacting on autistic and Alzheimer's pathologies. Transl Psychiatry. 2015;5:e501-e501. https://doi.org/10.1038/tp.2014.138.

23. Hadar A, Kapitansky O, Ganaiem M, Sragovich S, Lobyntseva A, Giladi E, et al. Introducing ADNP and SIRT1 as new partners regulating microtubules and histone methylation. Mol Psychiatry. 2021. https://doi.org/10.1038/s41380-021-01143-9.

24. Hacohen-Kleiman G, Sragovich S, Karmon G, Gao A, Grigg I, Pasmanik-Chor M, et al. Activity-dependent neuroprotective protein deficiency models synaptic and developmental phenotypes of autism-like syndrome. J Clin Invest. 2018;128:4956-69. https://doi.org/10.1172/jci98199.

25. Grigg I, Ivashko-Pachima Y, Hait TA, Korenková V, Touloumi O, Lagoudaki R, et al. Tauopathy in the young autistic brain: novel biomarker and therapeutic target. Transl Psychiatry. 2020;10:228. https://doi.org/10.1038/s41398-020-00904-4.

26. Vulih-Shultzman I, Pinhasov A, Mandel S, Grigoriadis N, Touloumi O, Pittel Z, et al. Activity-dependent neuroprotective protein snippet NAP reduces tau hyperphosphorylation and enhances learning in a novel transgenic mouse model. J Pharmacol Exp Ther. 2007;323:438-49. https://doi.org/10.1124/ jpet.107.129551.

27. Yang MH, Yang YH, Lu CY, Jong SB, Chen LJ, Lin YF, et al. Activity-dependent neuroprotector homeobox protein: a candidate protein identified in serum as diagnostic biomarker for Alzheimer's disease. J Proteomics. 2012;75:3617-29. https://doi.org/10.1016/j.jprot.2012.04.017.

28. Hess DT, Matsumoto A, Kim S-O, Marshall HE, Stamler JS. Protein S-nitrosylation: purview and parameters. Nat Rev Mol Cell Biol. 2005;6:150-66. https://doi.org/ 10.1038/nrm1569.

29. Amal H, Barak B, Bhat V, Gong G, Joughin BA, Wang X, et al. Shank3 mutation in a mouse model of autism leads to changes in the S-nitroso-proteome and affects key proteins involved in vesicle release and synaptic function. Mol Psychiatry. 2018. https://doi.org/10.1038/s41380-018-0113-6.

30. Amal H, Gong G, Gjoneska E, Lewis SM, Wishnok JS, Tsai LH, et al. S-nitrosylation of E3 ubiquitin-protein ligase RNF213 alters non-canonical Wnt/Ca+2 signaling in the P301S mouse model of tauopathy. Transl Psychiatry. 2019;9:44. https:// doi.org/10.1038/s41398-019-0388-7.

31. Zhou Y, Kaiser T, Monteiro P, Zhang X, Van der Goes MS, Wang D, et al. Mice with Shank3 mutations associated with ASD and schizophrenia display both shared and distinct defects. Neuron. 2016;89:147-62. https://doi.org/10.1016/j. neuron.2015.11.023.

32. Seneviratne U, Nott A, Bhat VB, Ravindra KC, Wishnok JS, Tsai LH, et al. S-nitrosation of proteins relevant to Alzheimer's disease during early stages of neurodegeneration. Proc Natl Acad Sci USA. 2016;113:4152-7. https://doi.org/ 10.1073/pnas.1521318113.

33. Khaliulin I, Kartawy M, Amal H. Sex differences in biological processes and nitrergic signaling in mouse brain. Biomedicines. 2020;8:124.

34. Rappsilber J, Mann M, Ishihama Y. Protocol for micro-purification, enrichment, pre-fractionation and storage of peptides for proteomics using StageTips. Nat Protoc. 2007;2:1896-906. https://doi.org/10.1038/nprot.2007.261.

35. Benjamini $Y$, Hochberg $Y$. Controlling the false discovery rate: a practical and powerful approach to multiple testing. J R Stat Soc Ser B (Methodol). 1995;57:289-300.

36. Szklarczyk D, Franceschini A, Wyder S, Forslund K, Heller D, Huerta-Cepas J, et al. STRING v10: protein-protein interaction networks, integrated over the tree of life. Nucleic Acids Res. 2015;43:D447-452. https://doi.org/10.1093/nar/gku1003.

37. Kartawy M, Khaliulin I, Amal H. Systems biology reveals reprogramming of the Snitroso-proteome in the cortical and striatal regions of mice during aging process. Sci Rep. 2020;10:1-11. 
38. Nakamura T, Lipton SA. Protein S-nitrosylation as a therapeutic target for neurodegenerative diseases. Trends Pharmacol Sci. 2016;37:73-84. https://doi.org/ 10.1016/j.tips.2015.10.002.

39. Foley TD, Koval KS, Olsen SH, Gallagher AG, Dennis ER. Protein S-nitrosylation: possible links between psychophysiological stress and neurodegeneration. Free Radic Biol Med. 2017;112:73-74.

40. Rizza S, Cardaci S, Montagna C, Di Giacomo G, De Zio D, Bordi M, et al. S-nitrosylation drives cell senescence and aging in mammals by controlling mitochondrial dynamics and mitophagy. Proc Natl Acad Sci USA. 2018;115: E3388-97.

41. Tripathi MK, Kartawy M, Amal H. The role of nitric oxide in brain disorders: autism spectrum disorder and other psychiatric, neurological, and neurodegenerative disorders. Redox Biol. 2020;34:101567.https://doi.org/10.1016/j. redox.2020.101567.

42. Hamoudi W, von Lendenfeld F, Kartawy M, Mencer S, Suloh H, Khaliulin I, et al. Regional differences in S-nitrosylation in the cortex, striatum, and hippocampus of juvenile male mice. J Mol Neurosci. 2021. https://doi.org/10.1007/s12031-02101792-z.

43. Amal $H$, Gong $G$, Yang $H$, Joughin BA, Wang $X$, Knutson CG, et al. Low doses of arsenic in a mouse model of human exposure and in neuronal culture lead to S-nitrosylation of synaptic proteins and apoptosis via nitric oxide. Int J Mol Sci. 2020;21:3948.

44. Kartawy M, Khaliulin I, Amal H. Systems biology reveals S-nitrosylationdependent regulation of mitochondrial functions in mice with Shank3 mutation associated with autism spectrum disorder. Brain Sci. 2021;11:677.

45. Nakamura T, Prikhodko OA, Pirie E, Nagar S, Akhtar MW, Oh CK, et al. Aberrant protein S-nitrosylation contributes to the pathophysiology of neurodegenerative diseases. Neurobiol Dis. 2015;84:99-108.

46. Nakamura T, Tu S, Akhtar MW, Sunico CR, Okamoto S, Lipton SA. Aberrant protein S-nitrosylation in neurodegenerative diseases. Neuron. 2013;78:596-614.

47. Yao D, Gu Z, Nakamura T, Shi ZQ, Ma Y, Gaston B, et al. Nitrosative stress linked to sporadic Parkinson's disease: S-nitrosylation of parkin regulates its $\mathrm{E} 3 \mathrm{ubi}$ quitin ligase activity. Proc Natl Acad Sci USA. 2004;101:10810-4. https://doi.org/ 10.1073/pnas.0404161101.

48. Chung KK, Dawson VL, Dawson TM. S-nitrosylation in Parkinson's disease and related neurodegenerative disorders. Methods Enzymol. 2005;396:139-50.

49. Haun $F$, Nakamura $T$, Shiu $A D$, Cho $D H$, Tsunemi $T$, Holland $E A$, et al. S-nitrosylation of dynamin-related protein 1 mediates mutant huntingtininduced mitochondrial fragmentation and neuronal injury in Huntington's disease. Antioxid Redox Signal. 2013;19:1173-84.

50. Nasyrova RF, Ivashchenko DV, Ivanov MV, Neznanov NG. Role of nitric oxide and related molecules in schizophrenia pathogenesis: biochemical, genetic and clinical aspects. Front Physiol. 2015;6:139.https://doi.org/10.3389/fphys.2015.00139.

51. Guang S, Pang N, Deng X, Yang L, He F, Wu L, et al. Synaptopathology involved in autism spectrum disorder. Front Cell Neurosci. 2018;12:470. https://doi.org/ 10.3389/fncel.2018.00470.

52. Mufson EJ, Mahady L, Waters D, Counts SE, Perez SE, DeKosky ST, et al. Hippocampal plasticity during the progression of Alzheimer's disease. Neuroscience. 2015;309:51-67. https://doi.org/10.1016/j.neuroscience.2015.03.006.

53. Scheff SW, Price DA, Ansari MA, Roberts KN, Schmitt FA, Ikonomovic MD, et al. Synaptic change in the posterior cingulate gyrus in the progression of Alzheimer's disease. J Alzheimers Dis. 2015;43:1073-90. https://doi.org/10.3233/jad141518.

54. Scheff SW, Price DA, Schmitt FA, Roberts KN, Ikonomovic MD, Mufson EJ. Synapse stability in the precuneus early in the progression of Alzheimer's disease. J Alzheimers Dis. 2013;35:599-609. https://doi.org/10.3233/jad-122353.

55. Gilbert J, Man HY. Fundamental elements in autism: from neurogenesis and neurite growth to synaptic plasticity. Front Cell Neurosci. 2017;11:359 https:// doi.org/10.3389/fncel.2017.00359.

56. van Spronsen M, Hoogenraad CC. Synapse pathology in psychiatric and neurologic disease. Curr Neurol Neurosci Rep. 2010;10:207-14. https://doi.org/ 10.1007/s11910-010-0104-8.

57. Dean B, Tawadros N, Seo MS, Jeon WJ, Everall I, Scarr E, et al. Lower cortical serotonin $2 \mathrm{~A}$ receptors in major depressive disorder, suicide and in rats after administration of imipramine. Int J Neuropsychopharmacol. 2014;17:895-906. https://doi.org/10.1017/s1461145713001648.

58. Rioux A, Fabre V, Lesch KP, Moessner R, Murphy DL, Lanfumey L, et al. Adaptive changes of serotonin $5-\mathrm{HT} 2 \mathrm{~A}$ receptors in mice lacking the serotonin transporter. Neurosci Lett. 1999;262:113-6.

59. Nichols CD. Serotonin 5-HT2A receptor function as a contributing factor to both neuropsychiatric and cardiovascular diseases. Cardiovasc Psychiatry Neurol 2009;2009.

60. Štrac DŠ, Pivac N, Mück-Šeler D. The serotonergic system and cognitive function. Transl Neurosci. 2016;7:35-49.
61. Lasser M, Tiber J, Lowery LA. The role of the microtubule cytoskeleton in neurodevelopmental disorders. Front Cell Neurosci. 2018;12:165.

62. Alhowikan AM. Activity-regulated cytoskeleton-associated protein dysfunction may contribute to memory disorder and earlier detection of autism spectrum disorders. Med Princ Pract. 2016;25:350-4.

63. Fukuda T, Yanagi S. Psychiatric behaviors associated with cytoskeletal defects in radial neuronal migration. Cell Mol Life Sci. 2017;74:3533-52.

64. Muñoz-Lasso DC, Romá-Mateo C, Pallardó FV, Gonzalez-Cabo P. Much more than a scaffold: cytoskeletal proteins in neurological disorders. Cells 2020;9. https://doi.org/10.3390/cells9020358.

65. Marques-Ramos A, Candeias MM, Menezes J, Lacerda R, Willcocks M, Teixeira A et al. Cap-independent translation ensures mTOR expression and function upon protein synthesis inhibition. Rna. 2017;23:1712-28. https://doi.org/10.1261/ rna.063040.117.

66. Sato A. mTOR, a potential target to treat autism spectrum disorder. CNS Neurol Disord Drug Targets. 2016;15:533-43. https://doi.org/10.2174/ 1871527315666160413120638.

67. Lee DY. Roles of mTOR signaling in brain development. Exp Neurobiol. 2015;24:177-85.

68. Ryskalin L, Limanaqi F, Frati A, Busceti CL, Fornai F. mTOR-related brain dysfunctions in neuropsychiatric disorders. Int J Mol Sci. 2018;19. https://doi.org/ 10.3390/ijms19082226.

69. Wong M. Mammalian target of rapamycin (mTOR) pathways in neurological diseases. Biomed J. 2013;36:40-50. https://doi.org/10.4103/2319-4170.110365.

70. Takei N, Nawa H. mTOR signaling and its roles in normal and abnormal brain development. Front Mol Neurosci. 2014;7.https://doi.org/10.3389/ fnmol.2014.00028.

71. Way SW, McKenna J, Mietzsch U, Reith RM, Wu HC, Gambello MJ. Loss of Tsc2 in radial glia models the brain pathology of tuberous sclerosis complex in the mouse. Hum Mol Genet. 2009;18:1252-65. https://doi.org/10.1093/hmg/ddp025.

72. Huang J, Manning BD. A complex interplay between Akt, TSC2 and the two mTOR complexes. Biochem Soc Trans. 2009;37:217-22. https://doi.org/10.1042/ bst0370217.

73. Winden KD, Ebrahimi-Fakhari D, Sahin M. Abnormal mTOR activation in autism. Annu Rev Neurosci. 2018;41:1-23.

74. Rosina E, Battan B, Siracusano M, Di Criscio L, Hollis F, Pacini L, et al. Disruption of mTOR and MAPK pathways correlates with severity in idiopathic autism. Transl Psychiatry. 2019;9:1-10.

75. Lopez-Rivera E, Jayaraman P, Parikh F, Davies MA, Ekmekcioglu S, Izadmehr S, et al. Inducible nitric oxide synthase drives mTOR pathway activation and proliferation of human melanoma by reversible nitrosylation of TSC2. Cancer Res. 2014;74:1067-78.

76. Biever A, Valjent E, Puighermanal E. Ribosomal protein S6 phosphorylation in the nervous system: from regulation to function. Front Mol Neurosci. 2015;8:75.

77. Palomer E, Buechler J, Salinas PC. Wnt signaling deregulation in the aging and Alzheimer's brain. Front Cell Neurosci. 2019;13:227.

78. Ma T, Tzavaras N, Tsokas P, Landau EM, Blitzer RD. Synaptic stimulation of mTOR is mediated by Wnt signaling and regulation of glycogen synthetase kinase-3. J Neurosci. 2011;31:17537-46.

79. Altomare DA, Khaled AR. Homeostasis and the importance for a balance between AKT/mTOR activity and intracellular signaling. Curr Med Chem. 2012;19:3748-62.

80. Inoki K, Ouyang H, Zhu T, Lindvall C, Wang Y, Zhang X, et al. TSC2 integrates Wnt and energy signals via a coordinated phosphorylation by AMPK and GSK3 to regulate cell growth. Cell. 2006;126:955-68.

81. Ma T, Hoeffer CA, Capetillo-Zarate E, Yu F, Wong H, Lin MT, et al. Dysregulation of the mTOR pathway mediates impairment of synaptic plasticity in a mouse model of Alzheimer's disease. PLoS ONE 2010;5. https://doi.org/10.1371/journal. pone.0012845 (2010).

82. Lafay-Chebassier C, Paccalin M, Page G, Barc-Pain S, Perault-Pochat MC, Gil R, et al. mTOR/p70S6k signalling alteration by Abeta exposure as well as in APPPS1 transgenic models and in patients with Alzheimer's disease. J Neurochem. 2005;94:215-25. https://doi.org/10.1111/j.1471-4159.2005.03187.x.

83. Oddo $\mathrm{S}$. The role of mTOR signaling in Alzheimer disease. Front Biosci (Sch Ed). 2012;4:941-52. https://doi.org/10.2741/s310.

84. Tramutola A, Triplett JC, Di Domenico F, Niedowicz DM, Murphy MP, Coccia R, et al. Alteration of mTOR signaling occurs early in the progression of Alzheimer disease $(A D)$ : analysis of brain from subjects with pre-clinical $A D$, amnestic mild cognitive impairment and late-stage AD. J Neurochem. 2015;133:739-49.

85. Kou $X$, Chen D, Chen N. Physical activity alleviates cognitive dysfunction of Alzheimer's disease through regulating the mTOR signaling pathway. Int J Mol Sci. 2019;20. https://doi.org/10.3390/ijms20071591.

86. Bockaert J, Marin P. mTOR in brain physiology and pathologies. Physiol Rev. 2015;95:1157-87. https://doi.org/10.1152/physrev.00038.2014. 
87. Deloulme JC, Janet T, Au D, Storm DR, Sensenbrenner M, Baudier J. Neuromodulin (GAP43): a neuronal protein kinase $C$ substrate is also present in 0-2A glial cell lineage. Characterization of neuromodulin in secondary cultures of oligodendrocytes and comparison with the neuronal antigen. J Cell Biol. 1990;111:1559-69. https://doi.org/10.1083/jcb.111.4.1559.

88. Holahan MR. A shift from a pivotal to supporting role for the growth-associated protein (GAP-43) in the coordination of axonal structural and functional plasticity. Front Cell Neurosci. 2017;11:266. https://doi.org/10.3389/fncel.2017.00266.

89. Rosskothen-Kuhl N, Illing RB. Gap43 transcription modulation in the adult brain depends on sensory activity and synaptic cooperation. PLoS ONE. 2014;9: e92624 https://doi.org/10.1371/journal.pone.0092624.

90. Remnestål J, Just D, Mitsios N, Fredolini C, Mulder J, Schwenk JM, et al. CSF profiling of the human brain enriched proteome reveals associations of neuromodulin and neurogranin to Alzheimer's disease. Proteomics Clin Appl. 2016;10:1242-53. https://doi.org/10.1002/prca.201500150.

91. Zaccaria KJ, Lagace DC, Eisch AJ, McCasland JS. Resistance to change and vulnerability to stress: autistic-like features of GAP43-deficient mice. Genes Brain Behav. 2010;9:985-96. https://doi.org/10.1111/j.1601-183X.2010.00638.x.

92. Wang CY, Lin HC, Song YP, Hsu YT, Lin SY, Hsu PC, et al. Protein kinase $\mathrm{C}$-dependent growth-associated protein 43 phosphorylation regulates gephyrin aggregation at developing GABAergic synapses. Mol Cell Biol. 2015;35:1712-26. https://doi.org/10.1128/mcb.01332-14.

93. Dai L, Zhao J, Yin J, Fu W, Chen G. Cell adhesion molecule 2 (CADM2) promotes brain metastasis by inducing epithelial-mesenchymal transition (EMT) in human non-small cell lung cancer. Ann Transl Med. 2020;8:465.

94. Frei JA, Andermatt I, Gesemann M, Stoeckli ET. The SynCAM synaptic cell adhesion molecules are involved in sensory axon pathfinding by regulating axon-axon contacts. J Cell Sci. 2014;127:5288-302.

95. Sheng L, Leshchyns' ka I, Sytnyk V. Neural cell adhesion molecule 2 promotes the formation of filopodia and neurite branching by inducing submembrane increases in Ca2+ levels. J Neurosci. 2015;35:1739-52.

96. Sheng L, Leshchyns'ka I, Sytnyk V. Neural cell adhesion molecule 2 (NCAM2)induced c-Src-dependent propagation of submembrane Ca2+ spikes along dendrites inhibits synapse maturation. Cereb Cortex. 2019;29:1439-59. https:// doi.org/10.1093/cercor/bhy041.

97. Scholz C, Steinemann D, Mälzer M, Roy M, Arslan-Kirchner M, Illig T, et al. NCAM2 deletion in a boy with macrocephaly and autism: cause, association or predisposition? Eur J Med Genet. 2016;59:493-8.

98. Leshchyns'ka I, Liew HT, Shepherd C, Halliday GM, Stevens CH, Ke YD, et al. A $\beta$-dependent reduction of NCAM2-mediated synaptic adhesion contributes to synapse loss in Alzheimer's disease. Nat Commun. 2015;6:1-18.

99. Wang Z, Jung JS, Inbar TC, Rangoussis KM, Faaborg-Andersen C, Coate TM, et al. The purinergic receptor $\mathrm{P} 2 \mathrm{rx} 3$ is required for spiral ganglion neuron branch refinement during development. eNeuro 2020;7. https://doi.org/10.1523/eneuro.0179-20.2020.

100. Naviaux RK, Zolkipli Z, Wang L, Nakayama T, Naviaux JC, Le TP, et al. Antipurinergic therapy corrects the autism-like features in the poly(IC) mouse model. PLoS ONE. 2013;8:e57380 https://doi.org/10.1371/journal.pone.0057380.

101. Godoy PA, Ramírez-Molina O, Fuentealba J. Exploring the role of P2X receptors in Alzheimer's disease. Front Pharmacol 2019;10. https://doi.org/10.3389/ fphar.2019.01330.

102. Yang J, Yang H, Liu Y, Li X, Qin L, Lou H, et al. Astrocytes contribute to synapse elimination via type 2 inositol 1,4,5-trisphosphate receptor-dependent release of ATP. Elife. 2016:5:e15043 https://doi.org/10.7554/eLife.15043.

103. Young LT, Kish SJ, Li PP, Warsh JJ. Decreased brain [3H] inositol 1, 4, 5-trisphosphate binding in Alzheimer's disease. Neurosci Lett. 1988;94:198-202.

104. Kish SJ, Li PP, Robitaille Y, Currier R, Gilbert J, Schut L, et al. Cerebellar [3H] inositol 1,4,5-trisphosphate binding is markedly decreased in human olivopontocerebellar atrophy. Brain Res. 1989;489:373-6.
105. Yokoyama K, Tezuka T, Kotani M, Nakazawa T, Hoshina N, Shimoda Y, et al. NYAP: a phosphoprotein family that links PI3K to WAVE1 signalling in neurons. EMBO J. 2011;30:4739-54. https://doi.org/10.1038/emboj.2011.348.

106. Guo H, Peng Y, Hu Z, Li Y, Xun G, Ou J, et al. Genome-wide copy number variation analysis in a Chinese autism spectrum disorder cohort. Sci Rep. 2017;7:44155.

107. Van Cauwenberghe C, Van Broeckhoven C, Sleegers K. The genetic landscape of Alzheimer disease: clinical implications and perspectives. Genet Med. 2016;18:421-30.

\section{ACKNOWLEDGEMENTS}

We thank the Satell Family Foundation for their generous support to the Amal Lab.

\section{AUTHOR CONTRIBUTIONS}

SM: bioinformatic and data analysis and preparing manuscript, MK: bioinformatic and data analysis, FL: data analysis and contributing to discussion, HS: biochemical validation of AD samples, MKT: biochemical validation of ASD samples, IK: data analysis, and HA: data analysis, supervision of the project, and writing the manuscript.

\section{COMPETING INTERESTS}

The authors declare no competing interests.

\section{ADDITIONAL INFORMATION}

Supplementary information The online version contains supplementary material available at https://doi.org/10.1038/s41398-021-01578-2.

Correspondence and requests for materials should be addressed to Haitham Amal

Reprints and permission information is available at http://www.nature.com/ reprints

Publisher's note Springer Nature remains neutral with regard to jurisdictional claims in published maps and institutional affiliations.

(i) Open Access This article is licensed under a Creative Commons Attribution 4.0 International License, which permits use, sharing, adaptation, distribution and reproduction in any medium or format, as long as you give appropriate credit to the original author(s) and the source, provide a link to the Creative Commons license, and indicate if changes were made. The images or other third party material in this article are included in the article's Creative Commons license, unless indicated otherwise in a credit line to the material. If material is not included in the article's Creative Commons license and your intended use is not permitted by statutory regulation or exceeds the permitted use, you will need to obtain permission directly from the copyright holder. To view a copy of this license, visit http://creativecommons. org/licenses/by/4.0/.

(c) The Author(s) 2021 